\title{
El desempeño institucional de la Comisión de Derechos Humanos del Estado de Puebla, 1993-2015*
}

\section{The institutional performance of the Human Rights Commission of the State of Puebla, 1993-2015}

\author{
Oscar Nicasio Lagunes López**
}

\section{RESUMEN}

En este artículo se describe el desempeño institucional de la Comisión de Derechos Humanos del Estado de Puebla, de 1993 a 2015. En general, se muestran las deficiencias institucionales en torno a la defensa de los derechos humanos en la entidad, entre las que destacan la ambigüedad y aplicación discrecional de los instrumentos de conclusión de quejas que tienen como finalidad restituir a las víctimas en el goce de sus derechos vulnerados. Ello, a raiz de que no se considera el nivel de satisfacción de las víctimas como criterio fundamental para dar solución a los expedientes de queja. En particular, se analizan dos recomendaciones emitidas por la Comisión, ya que éstas son el instrumento más fuerte del organismo para restablecer los derechos humanos de las víctimas, pero se encontró que las autoridades públicas del estado y las del organismo defensor simulan el cumplimiento de las recomendaciones, lo que genera una violación adicional a los derechos de los afectados, al no restituirseles sus derechos violentados.

Palabras clave: desempeño institucional, instrumentos de conclusión de quejas, recomendaciones en derechos humanos, Comisión de Derechos Humanos del Estado de Puebla, México.

\begin{abstract}
This article describes the institutional performance of the Human Rights Commission of the State of Puebla, 1993-2015. In general, the institutional deficiencies are shown around the defense of human rights in the entity, among which a spotlight is place on the ambiguity and discretionary application of the instruments for the conclusion of complaints that are intended to restore legal rights to the victims. This is due to the fact that a victim's level of satisfaction is not considered as a fundamental criterion for solving the file complaints. In particular, two recommendations issued by the Commission are analyzed, since they are the strongest instruments towards restoring the victims' human rights, but it was found that the public authorities of the state and those of the advocate agency simulate the fulfillment of the Recommendations, which creates an additional violation of the rights of those affected as their rights are not restored.
\end{abstract}

Keywords: institutional performance, instruments for the conclusion of complaints, recommendations in human rights, Human Rights Commission of the State of Puebla, Mexico.

\footnotetext{
*Artículo de investigación recibido el 4 de agosto de 2017 y aceptado para publicación el 8 de marzo de 2018

** Profesor Investigador en la Facultad de Derecho y Ciencias Sociales de la Benemérita Universidad Autónoma de Puebla, México. (oscar_lagunes@hotmail.com) orcid.org0000-0002-1449-8431
} 
SUMARIO: 1. Introducción / 2. Metodología / 3. Conceptos fundamentales / 4. El financiamiento público / 5. Control presupuestario y patrimonio propio / 6. La elección del ombudsman poblano / 7. Proceso de intervención y desempeño institucional / 8. El cumplimiento de las recomendaciones / 8.1 Recomendación 30/2009 / 8.2 Recomendación 15/2013 / 9. Conclusión / 10. Anexo: Cuadro de análisis de recomendaciones (037/1997, 26/2008, 30/2009 y 15/2013) / 11. Referencias

\section{INTRODUCCIÓN}

En este artículo se presentan los resultados obtenidos del análisis realizado sobre el desempeño de la Comisión de Derechos Humanos del Estados de Puebla (CDHEP) durante el periodo 1993-2015. En general, se exhiben las debilidades institucionales en relación con la defensa de los derechos humanos en la entidad poblana, entre las que pueden contarse la falta de autonomía institucional y la aplicación discrecional e imprecisa de los instrumentos de conclusión de quejas, que tienen como finalidad la restitución de los derechos humanos vulnerados de las víctimas, especialmente las recomendaciones. ${ }^{1}$ Lo anterior, a causa de que no se considera el nivel de satisfacción de las víctimas como el criterio principal para la conclusión de quejas. ${ }^{2}$ En particular, se analizan dos casos de recomendaciones emitidas por la Comisión, puesto que son el instrumento más fuerte del organismo para reparar los derechos vulnerados de las víctimas, constatándose un proceso de simulación en el cumplimiento de las recomendaciones, tanto por parte de las autoridades públicas del estado como de la propia institución defensora.

La estructura del artículo consiste en seis apartados. En el primero de ellos se abordan las perspectivas teóricas que permiten comprender el objeto de estudio de esta investigación: el desempeño institucional de la Comisión poblana. En la segunda, tercera y cuarta partes, se describe el proceso por el cual el Gobierno del Estado ejerce control político y económico sobre la

\footnotetext{
${ }^{1}$ No se explican en qué consisten dichos mecanismos, a excepción de las recomendaciones.

${ }^{2}$ Las víctimas son excluidas para la calificación del cumplimiento de las recomendaciones y del resto de instrumentos de conclusión de quejas. De acuerdo con Faz Mora, el nivel de satisfacción de las víctimas debe ser el criterio fundamental para la calificación del cumplimiento de las recomendaciones. Cfr. Faz Mora, Martín, Evaluación integral de la estructura y desempeño de la Comisión Estatal de Derechos Humanos (CEDH) de San Luis Potosí bajo parámetros internacionales, Tesis de Maestria en Derechos Humanos y Democracia, México, FLACSO-México, 2008 , p. 79.
} 
Comisión, contraviniendo con ello la autonomía jurídica de este organismo público; además, se explica su proceso de intervención en relación con la defensa y promoción de los derechos humanos. En la quinta parte se analizan dos recomendaciones emitidas por la Comisión poblana, que tienen el estado de cumplidas; ambas corresponden a violaciones graves a los derechos humanos. Finalmente, se realizan las conclusiones correspondientes.

\section{Metodología}

La metodología que se utiliza en este artículo es cuanti-cualitativa: estadísticas de datos duros y entrevistas a profundidad a los actores involucrados en la defensa y promoción de los derechos humanos en la entidad poblana, incluyendo a algunos funcionarios de la Comisión. Además, se analizan dos recomendaciones emitidas por la Comisión poblana (30/2009 y 15/2013), que tienen el estatus de cumplidas, para comprobar nuestra hipótesis de que su cumplimiento no repara los derechos vulnerados de las víctimas. Lo anterior, a raíz de que la finalidad de las recomendaciones es la restitución de los derechos humanos vulnerados de los afectados. Los datos duros fueron obtenidos de la revisión de los informes anuales de actividades de la Comisión y a través de solicitudes de acceso a la información pública.

\section{Conceptos fundamentales}

Existen algunos conceptos elementales para la comprensión del desempeño institucional de la Comisión poblana, como autonomía y recomendación. De acuerdo con algunos autores, la autonomía o independencia del Ombudsman es central para una institución dedicada a la salvaguarda y promoción de los derechos humanos, pues asegura buenos resultados en su gestión. En efecto, dice Venegas que "lo importante de dicha independencia no es solamente el plasmarla en un ordenamiento sino que sea observada en la práctica. En suma, independencia significa que el Ombudsman decide por sí mismo los problemas que investigará, las acciones que practicará y las resoluciones que emitirá”. ${ }^{3}$ En este sentido, las recomendaciones deberán ser autónomas, es decir, en la elaboración de dichas resoluciones no intervendrán autoridades

\footnotetext{
${ }^{3}$ Venegas, Sonia, Origen y devenir del ombudsman. ¿Una institución encomiable?, Universidad Autónoma de México, México, 1988, p. 41.
} 
distintas a las del organismo que las emite, como los partidos políticos u otros agentes del Gobierno.

La autonomía de los organismos defensores de derechos humanos implica que éstos no sufrirán sujeción alguna por parte de las autoridades públicas que son objeto de vigilancia; ${ }^{4}$ por medio de ésta, las instituciones públicas logran fortalecerse y adquirir legitimidad y credibilidad social. ${ }^{5}$ No obstante, objeta Álvarez Icaza, la eficacia y vigencia de los OPDH no se explica sólo con la autonomía de los mismos, sino también con "los procesos de ciudadanización y profesionalización, así como la transparencia en la gestión pública”. ${ }^{6}$

Por otro parte, las recomendaciones son el instrumento más fuerte de las Comisiones Defensoras de Derechos Humanos para concluir las quejas y reparar los derechos humanos vulnerados a las víctimas por parte de las autoridades públicas del estado o de los municipios. Deberán emitirse por violaciones graves a los derechos humanos, y su finalidad es restituir a las víctimas en el goce de sus derechos vulnerados. No tienen una naturaleza coercitiva, sino moral, por lo que su desacato no puede ser jurídicamente sancionable. En este mismo orden de ideas, Lachenal y Pulido explican que "las recomendaciones constituyen una forma de denuncia pública, la más relevante de hecho, con la que se busca ejercer toda la fuerza política, jurídica y moral del Ombudsman para combatir la impunidad, transformar las condiciones que permitieron esas violaciones a los derechos humanos y reparar a las víctimas". ${ }^{7}$ En esta misma línea, la Comisión Nacional de Derechos Humanos ( $C N D H)$ afirma que "a pesar de que las resoluciones no son obligatorias como las de los jueces, tienen una eficacia comprobada, dada su autoridad moral y la publicación de sus recomendaciones, de tal forma que la opinión pública ejerce presión para que éstas se cumplan". ${ }^{8}$

\footnotetext{
${ }^{4}$ Cfr. Lagunes López, Oscar Nicasio y Noriega Esparza, Guillermo, "Diagnóstico al desempeño de la Comisión Estatal de Derechos Humanos de Sonora, 1992-2012", Revista Legislativa de Estudios Sociales y de Opinión Pública, vol. IX, núm. 17, enero-junio, 2016, p. 73.

${ }^{5}$ Cfr. Álvarez Icaza Longoria, Emilio, "Situación de los Organismos Públicos de Derechos Humanos de las entidades federativas", en Ibáñez Aguirre, José Antonio y Salcedo González, Sandra (Coords.), Ombudsman: asignatura pendiente en México, Universidad Iberoamericana, México, 2013, p. 76.

${ }^{6}$ Ibidem.

${ }^{7}$ Lachenal, Cécile y Pulido, Miguel, "Un grito en el desierto. Notas sobre el (mal) uso del lenguaje institucional de la $\mathrm{CNDH}$, a la luz de algunas de sus recomendaciones", en Ibáñez Gutiérrez, José Antonio y Salcedo González, Sandra (Coords.), Ombudsman: asignatura pendiente en México, Universidad Iberoamericana, México, 2013, p. 22.

${ }^{8} \mathrm{CNDH}$, Manual de Derechos Humanos: conceptos elementales y consejos prácticos, Comisión Nacional de los Derechos Humanos-Cadenas Humanas, México, 2003, p. 38.
} 


\section{El financiamiento público}

Antes de analizar el presupuesto de la Comisión poblana, es importante indicar que el sistema Ombudsman mexicano es el más caro del mundo. ${ }^{9}$ Sin embargo, el presupuesto que se destina al sistema de defensa no jurisdiccional de los derechos humanos en México no se ha traducido en el óptimo desempeño de estos organismos. ${ }^{10}$

En relación a la autonomía financiera de las Comisiones de Derechos $\mathrm{Hu}-$ manos, existen trabajos que han probado empíricamente el control presupuestal al que están sometidas algunas de ellas, lo que limita sustancialmente su actuación. ${ }^{11}$ Este control tampoco es ajeno a la Comisión de Derechos $\mathrm{Hu}-$ manos del Estado de Puebla ni al resto de las Comisiones, puesto que la ley de este organismo deja abierta esa posibilidad al establecer que el presidente de la Comisión tiene la atribución de "elaborar el proyecto de presupuesto anual de egresos de la Comisión, presentarlo al Consejo Consultivo para su aprobación y remitirlo al Ejecutivo del Estado, para su inclusión en el presupuesto de egresos de la Entidad". ${ }^{12}$

Esta deficiencia debe subsanarse y adecuarse a la normatividad internacional, como está establecido en el artículo 72 de la Convención Americana de Derechos Humanos para el caso de la Corte Internacional de Derechos Humanos: “... la Corte elaborará su propio proyecto de presupuesto y lo someterá a la aprobación de la Asamblea General, por conducto de la Secretaría General. Esta última no podrá introducirle modificaciones". ${ }^{13}$ También Los Principios de París establecen este mismo principio al afirmar en relación con las Comisiones que:

\footnotetext{
${ }^{9}$ Cfr. Yáñez Velasco, David, "El sistema ombudsman más caro del mundo... ¿y el más ineficiente?" Espiral, Estudios sobre Estado y Sociedad, vol. XXII, núm. 63, mayo-agosto, 2015, pp. 194 y 214.

${ }^{10} \mathrm{Cfr}$. Mayer-Serra, Carlos Elizondo y Magaloni Kerpel, Ana L., Nuestros caros defensores de los derechos humanos: el caso de la Comisión Nacional de Derechos humanos, CIDE, México, 2010, pp. 8-15.

${ }^{11}$ Lagunes López, Oscar Nicasio y Poom Medina, Juan, "La negociación política de las recomendaciones. El caso de la Comisión Estatal de Derechos Humanos de Sonora, 1992-2012", Región y Sociedad, número especial 5, 2017, pp. 156-159.

${ }_{12}$ Congreso del Estado de Puebla, Ley de la Comisión de Derechos Humanos del Estado de Puebla, Artículo 15, Fracción X [las cursivas son nuestras]. Reforma publicada en el Periódico Oficial, 19 de mayo de 2014 [Consulta: 23/03/2017]. Disponible en: http://atlixco.gob.mx/atlixco/transparencia/2014/marconormativo/LeydelaComisióndeDerechosHumanosdelEstadodePuebla.pdf. En junio del 2017 se encontró que las únicas excepciones en establecer un candado a la injerencia del Ejecutivo y/o Congreso en el presupuesto de la Comisión son las leyes fundacionales de las Comisiones del Estado de México (Artículo 11), Campeche (Artículo 65), Veracruz (Artículo 24) y Yucatán (Artículo 5).

${ }^{13}$ ColDH, Informe anual 2012, San José Costa Rica, Corte Interamericana de Derechos humanos, 2012, p. 93. [Consulta: 07/04/2017]. Disponible en http://www.corteidh.or.cr/docs/informes/spa_2012.pdf. Las cursivas son nuestras.
} 
la institución nacional dispondrá de una infraestructura apropiada para el buen desempeño de sus funciones, y en particular de créditos suficientes. Esos créditos deberán destinarse principalmente a la dotación de personal y locales propios, a fin de lograr la autonomía respecto del Estado y no estar sujeta a controles financieros que podrían limitar su independencia. $^{14}$

\section{Control presupuestario y PATRimonio Propio}

El presupuesto y el patrimonio propios, como se establece en el artículo 142 de la Constitución Política del Estado de Puebla y en el artículo 2 de la Ley de la Comisión, son elementos importantes que el Legislativo ha establecido para que la Comisión pueda cumplir con sus funciones. Es más, pueden servir de indicador para medir la relevancia que tienen los derechos humanos para el Gobierno estatal y el grado de autonomía de la institución encargada de promoverlos y defenderlos. Por estas razones, es necesario revisar si la Comisión poblana cuenta con patrimonio propio y la evolución de su presupuesto a lo largo de sus 23 años de labores. En este sentido, cabe resaltar que el edificio que actualmente alberga al Organismo Defensor Local, conocido como Casa Agustín Arrieta (calle 5 poniente, 339, centro de Puebla), fue prestado por el Gobierno del Estado el 11 de mayo de 2012, en el cual comenzarían una nueva etapa a partir del 1 de enero de 2013. ${ }^{15}$

Lo anterior pone en evidencia que la Comisión no cuenta con un inmueble propio para su funcionamiento, como lo establece el mandato legal que la constituye, lo cual merma su autonomía al depender del Gobierno, no sólo porque éste último puede intervenir, de hecho lo hace, reduciendo el monto del presupuesto de egresos que anualmente el organismo defensor solicita al Ejecutivo estatal, sino también porque en cualquier momento puede exigir la devolución del inmueble en el que está alojada la institución. ${ }^{16}$ El problema ha

\footnotetext{
${ }^{14}$ Asamblea General de las Naciones Unidas, Principios de París o Principios Relativos al Estatuto y Funcionamiento de las Instituciones Nacionales de Protección y Promoción de los Derechos Humanos, París, ONU, 1991, Apartado B, núm. 2. [Consulta: 01/08/2017]. Disponible en http://hrlibrary.umn.edu/instree/Sparisprinciples.pdf. Las cursivas son nuestras. El control que ejercen los partidos politicos y los gobernadores locales sobre las Comisiones de Derechos humanos del pais ha sido suficientemente documentado. Cfr. Lachenal, Cécile, Martínez, Juan Carlos y Moguel, Miguel, Los Organismos Públicos de Derechos Humanos en México. Nuevas instituciones, viejas prácticas, Fundar, México, 2009, p. 25.

${ }^{15}$ Cfr. CDHEP, Informe anual de actividades 2012, Comisión de Derechos Humanos del Estado de Puebla, Puebla, 2013, p. 61. Anteriormente la Comisión poblana rentaba otro edificio.

${ }^{16}$ En el año 2015, el Congreso del Estado de Puebla aprobó a la CDHEP un presupuesto de $\$ 21,034,470.00$. Sin embargo, este monto fue reducido en $\$ 5,430,770.62$, por lo que el organismo sólo obtuvo para este año un presupuesto
} 
sido tan evidente que en el informe 1999-2000 emitido por la Comisión poblana se hacían observaciones importantes en relación con la indisposición del Congreso local para reformar la ley de la Comisión y reconocer su autonomía. ${ }^{17}$

Por otro lado, la Comisión poblana es la que menos porcentaje recibe del Presupuesto de Egresos del Gobierno del Estado (0.03\%) en comparación con el porcentaje del presupuesto asignado al resto de las Comisiones Estatales de Derechos Humanos del país. ${ }^{18}$ De hecho, su presupuesto anual ha sido fuertemente recortado, ya que el porcentaje que recibe del presupuesto del Gobierno estatal ha experimentado una reducción constante a lo largo del periodo analizado. La CDHEP ha recibido durante el periodo 1993-2015 un promedio anual del 0.11\% del presupuesto del Gobierno estatal. En 1994 recibió el 0.19\%, pero en los últimos seis años de gestión, 2010-2015, se le asignó el $0.03 \%$ de ese presupuesto. ${ }^{19}$ Esto demanda que se haga una adecuación al artículo 15, fracción X, de la ley de la Comisión poblana, para impedir que el Ejecutivo o el Congreso realicen recortes presupuestales y le otorguen cada vez menos porcentaje del presupuesto estatal. Además de incorporar esta restricción, dicho artículo deberá indicar que el presupuesto que se le autorice a la Comisión no será menor al asignado en el año inmediato anterior ni tampoco inferior al 0.11\% del presupuesto anual del estado. De esta manera, los dos poderes señalados sólo podrían incrementar el presupuesto del organismo pero no reducirlo. Lo anterior es importante puesto que "una instancia que vea condicionada su supervivencia económica a cierto tipo de comportamientos ante quienes le asignan los recursos autorrestringirá su crítica en aras de su supervivencia, lo que le impedirá actuar para prevenir y sancionar

\footnotetext{
de $\$ 15,603,699.38$, es decir, $25.82 \%$ menos del original. La Comisión aduce que este recorte en su financiamiento se debió a "la situación económica que atravesaron el país y el estado durante el año 2015, a consecuencia de la caída de los precios del petróleo; entre otros aspectos, provocó que el subsidio para el ejercicio fiscal 2015 que recibió la Comisión de Derechos Humanos del Estado de Puebla sufriera un recorte". CDHEP, Informe anual de actividades 2015, Comisión de Derechos Humanos del Estado de Puebla, Puebla, 2016, p. 89.

${ }^{17}$ Cfr. CDHEP, VII informe anual de actividades 1999-2000, Comisión Estatal de Defensa de los Derechos Humanos, Puebla, 2000, pp. 15-16. Esta postura crítica del Ombudsman poblano, Jaime Juárez Hernández, se volvería a repetir en el último informe de su gestión 2000-2001. Posteriormente ya no se encontraría en ningún otro documento del organismo, a pesar del evidente control a la que está sujeta la institución.

${ }^{18}$ Este dato se obtuvo al analizar los porcentajes del presupuesto de egresos de los gobiernos estatales destinados a los OPDH durante los años 2012, 2015 y 2016.

${ }^{19}$ Cfr. Lagunes López, Oscar Nicasio, "La simulación en el cumplimiento de las recomendaciones. El caso de la Comisión de Derechos Humanos del Estado de Puebla, México, 1993-2015", Revista Latinoamericana de Derechos Humanos, vol. XXVIII, núm. 1, 2017, pp. 152-153 [Consulta: 15 de diciembre de 2017]. Disponible en: http://www. revistas.una.ac.cr/index.php/derechoshumanos/article/view/9679/11842.
} 
las violaciones a derechos humanos, así como para promover y difundir una cultura de los derechos humanos". ${ }^{20}$

\section{La elección del ombudsman poblano}

Hasta hace poco, los presidentes de las Comisiones de Derechos Humanos eran elegidos por el Ejecutivo del estado, por medio de una terna de candidatos que éste proponía al Congreso. ${ }^{21}$ Las reformas a la Constitución y a las legislaciones de estos organismos aún no logran democratizar el proceso de elección de los Ombudsman en México, pues no porque éste sea electo por el Congreso se evitará que los partidos políticos de mayoría y el Ejecutivo sigan controlando su designación. En el caso de Puebla, la ley de la Comisión deja abierta la posibilidad de que ex servidores públicos puedan ocupar el cargo de Ombudsman, pues no prohíbe que al término de su gestión ocupen dicho puesto. ${ }^{22}$

En el caso de la Comisión poblana, algunos de sus expresidentes han sido designados por el titular del Ejecutivo del estado como magistrados presidentes del Supremo Tribunal de Justicia del Estado de Puebla. Éste fue el caso de León Dumit Espinal, quien estuvo al frente del Supremo Tribunal de Justicia del Estado de Puebla, antes y después de su gestión como presidente de la Comisión. Otro caso fue el de Jorge Ramón Morales Díaz, ex Ombudsman local, quien fue presentado en la terna para magistrado del Supremo Tribunal de Justicia del Estado y electo por el pleno del Congreso el 15 de julio de 2011. ${ }^{23}$ Anteriormente se desempeñó en diferentes cargos dentro del Poder Judicial del estado; el 15 de mayo de 1993 fue nombrado juez propietario adscrito al Juzgado Séptimo Penal del municipio de Puebla, el 1 de agosto de 2007 reanudó actividades en el Juzgado de lo Civil y de lo Penal del distrito judicial de Chalchicomula de Sesma, y el 3 de agosto de 2008 se cambió al Juzgado Sexto Penal en Puebla. ${ }^{24}$

\footnotetext{
${ }^{20}$ Lachenal, Cécile, Martínez, Juan C. y Moguel, Miguel, op. cit., p. 47.

${ }^{21}$ A partir del 20 de marzo de 2015, el cargo del Ombudsman guerrerense dejó de ser vitalicio. A la fecha, 24 de febrero de 2017, Guanajuato es el único caso de intervención del Ejecutivo estatal en la designación del Ombudsman local (Artículo 12 de la Ley de la Comisión). De acuerdo con un estudio reciente, hasta el año 2013 los presidentes de las comisiones de Guerrero, Hidalgo, Tabasco y Tamaulipas eran propuestos por el Titular del Ejecutivo local, Cfr. Álvarez Icaza Longoria, Emilio, op. cit., en José Antonio Ibáñez Gutiérrez y Sandra Salcedo González (Coords.), Ombudsman: asignatura pendiente en México, Universidad Iberoamericana, México, 2013, p. 79.

${ }^{22}$ Cfr. Congreso del Estado de Puebla, Ley de la Comisión..., Artículo 10.

${ }^{23}$ Congreso del Estado de Puebla, Segundo periodo Ordinario de Sesiones, versión estenográfica, viernes 15 de julio de 2011.

${ }^{24}$ Shanik, David, "Jorge Ramón Díaz nuevo magistrado del TSJ Puebla", Puebla Online, 15 de julio de 2011. [Consulta: 22/02/2017]. Disponible en http://www.pueblaonline.com.mx/index.php?option=com_k2\&tview=item\&tid=15194:jo
} 
En toda su historia, la CDHEP ha tenido seis presidentes: León Dumit Espinal (28/07/1993-27/07/1996), Jaime Juárez Hernández (primer periodo: 28/07/1996-27/07/1999; segundo periodo: 28/07/1999-27/07/2002), Jorge Ramón Morales Díaz (28/07/2002-27/07/2005), José Manuel Cándido Flores Mendoza (28/07/2005-27/07/2008), Marcia Maritza Bullen Navarro (28/07/2008-27/07/2011) y Adolfo López Badillo (primer periodo: 28/07/201127/07/2014; segundo periodo: 28/07/2014-27/07/2019). ${ }^{25}$ Originalmente se estipulaba que el Ombudsman poblano durara en el cargo tres años, ${ }^{26}$ pero la reforma a la ley de la Comisión, publicada el 19 de mayo de 2014, amplió a cinco años el periodo de gestión de los presidentes del organismo. La ratificación de su titular está contemplada en su normatividad y se ha aplicado en un par de ocasiones. ${ }^{27}$

Previo a la reforma de la ley de la Comisión publicada en el Diario Oficial el 24 de marzo del 2000, el Ejecutivo del estado enviaba al Congreso una terna de candidatos a presidentes de la Comisión; ${ }^{28}$ a partir de la reforma en comento, dicha designación pasó al Legislativo local. ${ }^{29}$ En cuanto al Consejo consultivo, la elección de este cuerpo colegiado integrado por cinco ciudadanos "de reconocido prestigio en la sociedad [...] con conocimiento en materia de derechos humanos" corresponde al Congreso del Estado. ${ }^{30}$ El artículo 10 de la ley de la Comisión deja abierta la posibilidad de que funcionarios del Gobierno participen en su conformación: “... cuando menos, tres de éstos no deberán desempeñar cargo o comisión como servidores públicos, durante el tiempo de su gestión”. Sin embargo, la intervención del gobernador en la elección del titular de la Comisión y de los consejeros ha continuado a pesar de la reforma, pues estos no han surgido de las organizaciones de la sociedad civil organizada, sino que han sido personas afines al Ejecutivo estatal, lo

\footnotetext{
rgeramónd\%C3\%ADaz-nuevo-magistrado-del-tribunal-superior-de-justicia-de-pueblactltemid=127.

${ }^{25}$ Cfr. Respuesta a solicitud de información pública por sistema Infomex Puebla, con número de folio 00701016, del 19 diciembre de 2017.

${ }^{26} \mathrm{Cfr}$. Congreso del Estado de Puebla, Ley que crea la Comisión..., Artículo 11. Publicada en el Periódico Oficial, tomo CCXLVII, núm. 49, segunda sección, del 18 de diciembre de 1992 [Consulta: 28/07/2017]. Disponible en http://transparencia.cdhpuebla.org.mx/index.php/articulo-11/4-articulo-i; Congreso del Estado de Puebla, Ley de la Comisión de Derechos Humanos del Estado de Puebla, artículo 2.

${ }^{27}$ Cfr. Congreso del Estado de Puebla, Ley de la Comisión de Derechos Humanos del Estado de Puebla, artículo 8, fracción IV. En toda la historia de la CDHEP, sólo han sido reelectos para un segundo periodo al frente del organismo Jaime Juárez Hernández y Adolfo López Badillo.

${ }^{28} \mathrm{Cfr}$. Congreso del Estado de Puebla, Ley que crea la Comisión..., artículo 10.

${ }^{29}$ Cfr. Congreso del Estado de Puebla, Ley de la Comisión..., artículo 8. La ley de la Comisión ha sido reformada cuatro veces: 24/03/2000, 11/09/2006, 14/01/2009 y 19/05/2014.

30 Ibidem, artículo 10.
} 
que implica que la Comisión no sea realmente independiente del gobierno ni autónoma. $^{31}$

\section{Proceso de intervención y desempeño institucional}

La Comisión Estatal de Defensa de los Derechos Humanos fue creada el 18 de diciembre de 1992, pero el 28 de febrero de 2014 fue modificada su denominación a Comisión de Derechos Humanos del Estado de Puebla. ${ }^{32}$ En el artículo 2 de la ley de la Comisión se le constituye como "un organismo público autónomo, con personalidad jurídica y patrimonio propios. Estará dotado de autonomía operativa, de gestión, decisión y presupuestaria; tiene como objeto la protección, respeto, vigilancia, prevención, observancia, promoción, defensa, estudio y divulgación de los derechos humanos, según lo previsto por el orden jurídico mexicano". ${ }^{33}$ Esta ley también establece cuál es la competencia de la institución defensora: recibir y tramitar quejas de parte o de oficio por presuntas violaciones a los derechos humanos ("por actos u omisiones"), cometidas por las autoridades públicas del estado ${ }^{34}$ y de los municipios, a excepción de las del Poder Judicial. ${ }^{35}$ La legislación vigente también limita al organismo para conocer de actos y resoluciones de organismos y autoridades electorales, resoluciones de carácter jurisdiccional y para ser consultada sobre la interpretación de las disposiciones constitucionales. ${ }^{36}$ Es importante resaltar que el reglamento interno de la Comisión la considera como un órgano de la sociedad y defensora de ésta. ${ }^{37}$ Por otra parte, la ley de la Comisión de 1992 considera

\footnotetext{
${ }^{31}$ Entrevista a Rubén Alberto Curiel Tejeda, coordinador de la Maestría en Derechos Humanos, de la Universidad Iberoamericana, Puebla, 22 de febrero de 2017.

${ }^{32}$ Congreso del Estado de Puebla, Constitución Política del Estado Libre y Soberano de Puebla, Artículo 142. Reforma publicada en el Periódico Oficial, Tomo CDXXXV, No. 11, Séptima Sección, del 25 de julio de 2011. [Consulta: 28/07/2017]. Disponible en http://www.cdhpuebla.org.mx/transparencia/images/fraccionl/Periodico_Oficial_Estado_AutonomiaCDHEP.pdf; Congreso del Estado de Puebla, Ley de la Comisión..., Artículo 2. Congreso del Estado de Puebla, Ley que crea la Comisión..., Artículo 2.

${ }^{33}$ Congreso del Estado de Puebla, Ley de la Comisión..., Artículo 2. Las cursivas son nuestras.

${ }^{34}$ Ibídem, Artículos 4 y 13.

${ }^{35}$ Congreso del Estado de Puebla, Reglamento Interno de la Comisión de Derechos Humanos del Estado de Puebla, Artículo 11. Periódico Oficial, Tomo CDLXVI, Número 11, Segunda Sección, "Cuatro Veces Heroica Puebla de Zaragoza", viernes 28 de febrero de 2014. [Consulta: 02/02/2017]. Disponible en http://transparencia.cdhpuebla.org.mx/ index.php/articulo-11/4-articulo-i.

${ }^{36}$ Congreso del Estado de Puebla, Ley de la Comisión..., Artículo 14. Otros ámbitos de incompetencia del organismos defensor están señalados en el artículo 105, fraccs. I-XI del reglamento interno.

${ }^{37}$ Congreso del Estado de Puebla, reglamento interno de la Comisión..., artículo 3, reforma del 28 de febrero de 2014.
} 
que "la autoridad moral de la institución [...] es por sí misma el fundamento de su propia eficacia". ${ }^{38}$

El reglamento interno de la Comisión poblana hace explícito que las violaciones graves a los derechos humanos son aquellas acciones $\mathrm{u}$ omisiones en las que se atenta contra "la vida [...] la integridad física o psíquica $u$ otras que se consideren especialmente graves por el número de afectados o sus posibles consecuencias". ${ }^{39}$ Aunque el reglamento interno y la ley de la Comisión no especifican que las recomendaciones deberán ser emitidas por violaciones graves a los derechos humanos, sino sólo por "violaciones a los derechos humanos", ${ }^{40}$ la práctica común de la Comisión es emitirlas también por casos de violaciones graves a los derechos humanos ya mencionadas. En el caso de la conclusión de los expedientes de quejas por otros mecanismos como la conciliación, por ejemplo, la normatividad que rige la Comisión sí aclara que estos se aplicarán cuando no se trate de casos graves de violaciones a los derechos humanos. ${ }^{41}$

De acuerdo con el reglamento interno de la Comisión, artículo 104, las causas de conclusión de quejas son por a) incompetencia de la Comisión para conocer de la queja, b) orientación al no tratarse de una violación a los derechos humanos, c) desistimiento expreso del quejoso, d) falta de interés del quejoso en que continúe el proceso, e) acuerdo de acumulación de expedientes, f) solución por conciliación o durante el trámite, g) por quedarse la queja sin materia, h) recomendación, i) documento de no responsabilidad y por otros más contenidos en este ordenamiento.

La Comisión deberá "procurar la conciliación entre los quejosos y las autoridades señaladas como responsables, así como la inmediata solución

\footnotetext{
${ }^{38}$ Congreso del Estado de Puebla, Ley que Crea la Comisión Estatal de Defensa de los Derechos Humanos, Considerando.

${ }^{39}$ Congreso del Estado de Puebla, Reglamento Interno de la Comisión de Derechos Humanos del Estado de Puebla, artículo 97.

${ }^{40}$ Cfr. Ibíd., artículo 108; Congreso del Estado de Puebla, Ley de la Comisión..., artículos 44 y 46 . Los estudios de Emilio Álvarez Icaza Longoria dejan en claro que las recomendaciones no sólo se emiten por violaciones graves a los derechos humanos. Cfr. Para entender los derechos humanos en México, Nostra, México, 2009, p. 68; Idem, "Situación de los Organismos Públicos de Derechos Humanos de las Entidades Federativas", en Ibáñez Aguirre, José Antonio y Salcedo González, Sandra (Coords.), Ombudsman: asignatura pendiente en México, Universidad Iberoamericana, México, 2013, p. 102.

${ }^{41}$ Congreso del Estado de Puebla, Reglamento interno..., artículo 97. Los expedientes de quejas que se concluyen por otros mecanismos de conclusión de quejas, tales como los acuerdos de no responsabilidad y la resolución durante el trámite, deberán aplicarse para casos de violaciones no graves a los derechos humanos, aunque la normatividad que rige a la Comisión poblana no lo explicita claramente.
} 
del conflicto planteado, cuando la naturaleza del caso lo permita"; ${ }^{42}$ también podrá concluir las quejas por “acuerdos de trámite”, con la finalidad de que las autoridades públicas comparezcan y aporten la información requerida. ${ }^{43}$ "La recomendación será pública y autónoma”, ${ }^{44}$ pero no será obligatoria para las autoridades receptoras, que tendrán quince días para aceptarla y otros quince días para darle cumplimiento. Este "plazo podrá ser ampliado a criterio de la Comisión". ${ }^{45}$ Las autoridades que no cumplan las recomendaciones "se harán del conocimiento de la opinión pública". ${ }^{46}$ La ley de la Comisión indica expresamente que en la recomendación "se deberán señalar las medidas necesarias para una efectiva restitución de los afectados en sus derechos fundamentales, y en su caso, para la reparación de los daños y perjuicios que se hubiesen ocasionado". ${ }^{47}$

En todo el periodo de estudio, la CDHEP recibió un total de 203562 solicitudes de intervención, pero sólo 16.79\% (34 182) calificó como quejas, es decir, como presuntas violaciones a los derechos humanos. De las quejas recibidas, 36.04\% (12 320) se concluyó mediante el procedimiento, $14.50 \%$ por no violación a los derechos humanos, $12.71 \%$ por falta de interés del quejoso, 7.91\% por desistimiento expreso, 3.32\% (1 135) por recomendaciones, 0.46\% mediante conciliación y $0.17 \%$ por acuerdo de no responsabilidad. Hasta el 31 de diciembre de 2016 se había cumplido 96.83\% de las recomendaciones emitidas. Con estos instrumentos de conclusión de quejas, la Comisión informó haber dado conclusión a 96.5\% de los expedientes de quejas. ${ }^{48}$ Los datos analizados ponen de manifiesto que el mecanismo favorito del organismo defensor para concluir las quejas es la resolución durante el procedimiento, con más de un tercio de quejas resueltas mediante este instrumento, y no la conciliación, como lo establece la institución en su legislación. ${ }^{49}$

\footnotetext{
${ }^{42}$ Congreso del Estado de Puebla, Ley de la Comisión..., artículo 13. Cfr. Congreso del Estado de Puebla, Reglamento Interno..., artículo 39, fracc. VII. Las cursivas son nuestras.

${ }^{43}$ Congreso del Estado de Puebla, Ley de la Comisión..., artículo 43.

${ }^{44}$ Ibidem.

${ }^{45}$ lbid.

${ }^{46}$ Ibid., artículo 47.

${ }^{47}$ Congreso del Estado de Puebla, Ley de la Comisión..., artículo 44. Las cursivas son nuestras.

${ }^{48} \mathrm{Cfr}$. Respuesta de la CDHEP a solicitud de información pública con número de folio infomex 00700616, del 19 de diciembre de 2016; Solicitud de Información pública núm. de folio Infomex 00093517, respuesta de la CDHEP con Oficio No. CDH/DPIT/029/2017, del 7 de marzo de 2017; solicitud de Información pública núm. de folio Infomex 00093617, respuesta de la CDHEP con Oficio No.: CDH/DPIT/035/2017, del 7 de marzo de 2017.

${ }^{49}$ Tanto la Ley de la Comisión como el Reglamento Interno indican que la Comisión deberá "procurar la conciliación entre los quejosos", como mecanismo de conclusión de quejas, Cfr. Congreso del Estado de Puebla, Ley de la Comisión..., Artículo 13; Ídem, Reglamento Interno..., Artículo 39, Fracc. VII.
} 
A pesar de haberse detectado presuntas violaciones a los derechos humanos como consta por la emisión de quejas, llama la atención que sólo un pequeño porcentaje se concluyó por la emisión de recomendaciones. Esto significa, en particular, que la Comisión detecta muy pocos casos de violaciones graves a los derechos humanos, lo cual es cuestionable. Por otro lado, la resolución durante el procedimiento o durante el trámite es un mecanismo ambiguo que podría esconder el rechazo de quejas por presunta violación a los derechos humanos, como lo ha reconocido Marcia Maritza Bullen Navarro, ex Ombudsman de la Comisión poblana. ${ }^{50}$ Algo similar sucede entre las solicitudes de intervención y las quejas, pues mientras el número de las primeras ha ido creciendo cada año, el porcentaje del número de las segundas ha ido en franco descenso. ${ }^{51}$

En relación con las quejas recibidas por año, el porcentaje de recomendaciones emitidas ha mostrado en el tiempo una tendencia descendente (figura 2), a pesar de que el número de quejas recibidas presenta una tendencia incremental en el periodo analizado (figura 1). En 1993, la Comisión recibió sólo 239 quejas y en 1994, 488 expedientes de quejas. Los años en que más quejas ha recibido el organismo fueron: 2004, con 2 927; 2005, con 2 595; y 2006, con 2253 quejas. En 2015, el organismo apenas logró abrir 1435 expedientes de quejas, lo cual significa un descenso de poco más de la mitad de quejas en relación al 2004, año en que se abrieron más expedientes de todo el periodo. En cuanto a las recomendaciones, el porcentaje más alto de quejas que se resolvieron mediante este mecanismo tuvo lugar en 1994, con 7.99\% de las quejas (39 recomendaciones) recibidas; el segundo lugar fue en 1998, con 6.73\% (50 recomendaciones). En cambio, 2012 fue el año con el menor porcentaje de quejas (1.44\%) resueltas vía recomendación (26 recomendaciones).

\footnotetext{
${ }^{50}$ Cfr. Entrevista a Marcia Maritza Bullen Navarro, ex Presidenta de la Comisión de Derechos Humanos del Estado de Puebla, periodo 2008-2011, 8 de marzo de 2017.

${ }^{51}$ Cfr. Respuesta a solicitud de información pública infomex folio núm. 00700816 del 19 de diciembre de 2016; Respuesta a solicitud de información pública infomex folio núm. 00700916 del 19 de diciembre de 2016.
} 
Figura 1.

Número de quejas recibidas 1993-2015.

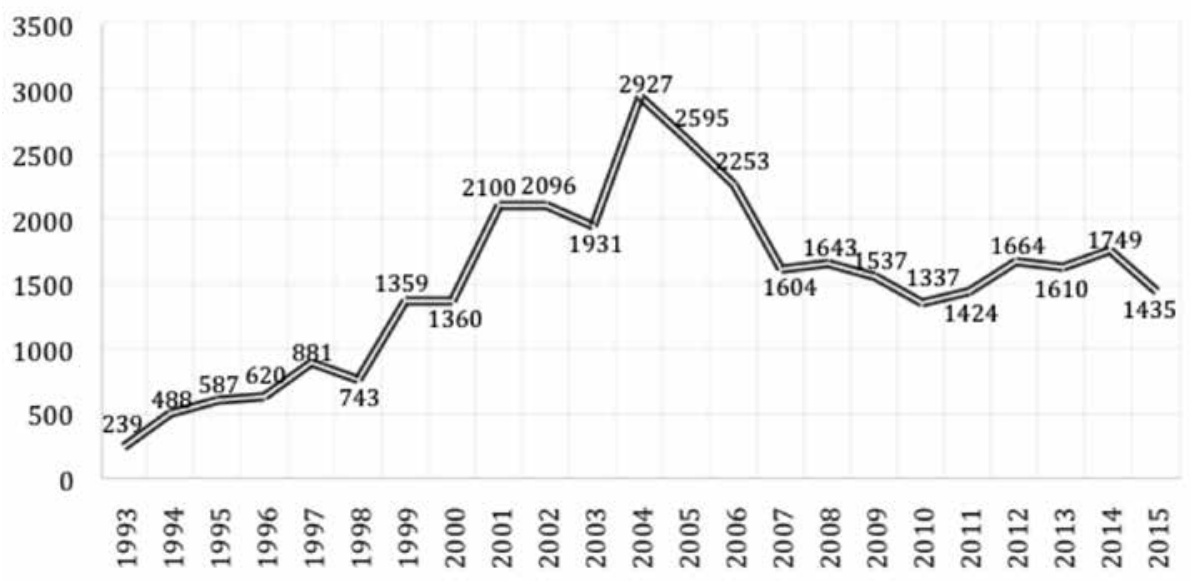

Fuente: Elaboración propia con base en la respuesta de solicitud de información pública. ${ }^{52}$

Figura 2.

Porcentaje de recomendaciones emitidas 1993-2015.

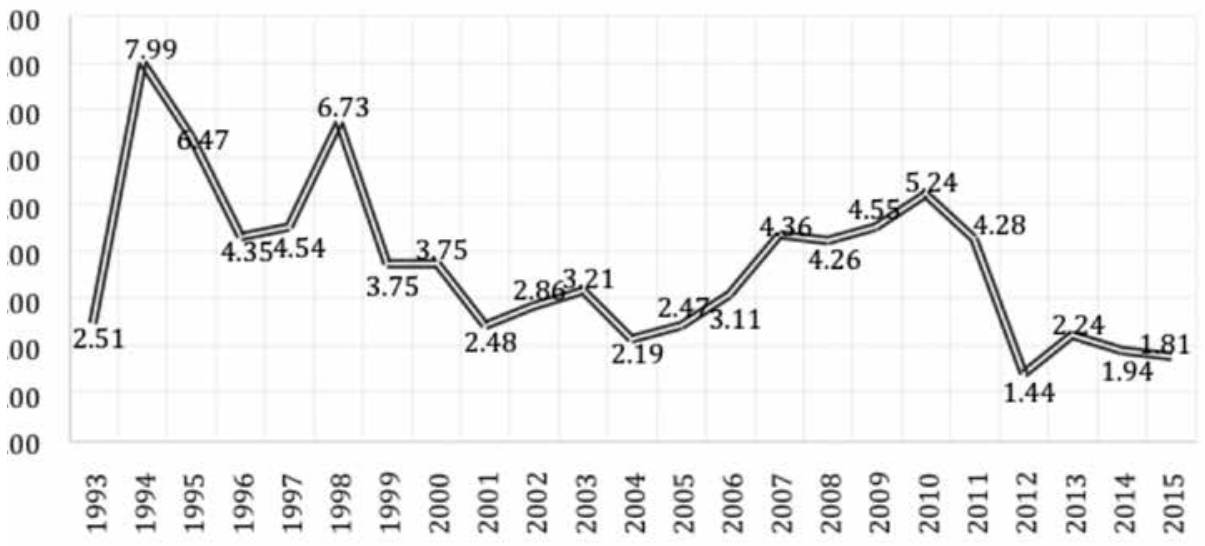

Fuente: Elaboración propia con base en la respuesta de solicitud de información pública. ${ }^{53}$

\footnotetext{
${ }^{52}$ Respuesta a solicitud de información pública Infomex, folio 00700816, del 19 de diciembre de 2016.

${ }^{53}$ Respuesta a solicitud de información pública Infomex, folio 00700016, del 19 de diciembre de 2016.
} 
En general, se puede observar un descenso en el tiempo del porcentaje de quejas que se concluyen mediante la emisión de una recomendación. Esto implica que a lo largo del periodo existe un aumento importante del número de presuntas violaciones a los derechos humanos o quejas (figura 1), a la vez que un decremento en el número de casos graves de violaciones a los derechos humanos o recomendaciones (figura 2). Lo esperado, como consecuencia lógica, es que al incrementarse el número de quejas también aumente el porcentje de número de recomendaciones emitidas en relación con las quejas. En entrevista, un funcionario de la Comisión adujo que "existen muchos casos en que se emitieron recomendaciones por casos no graves de derechos humanos". ${ }^{4}$ De esta manera, la recomendación se trivializó y perdió fuerza como un instrumento eficaz para legitimar el trabajo del organismo. Esto ha conducido, de acuerdo con su dicho, a la reducción del número de recomendaciones que actualmente se emiten.

En cuanto a los derechos humanos presuntamente más violados en las quejas y en las recomendaciones, cabe decir que los informes del periodo 1993-2011 hablan de "hechos violatorios a los derechos humanos" señalados en las quejas recibidas, mientras que los informes del periodo 2012-2015 emplean la categoría "derechos humanos presuntamente vulnerados", lo cual conlleva que en ambos casos se empleen categorías de clasificación de violaciones distintas, puesto que no es lo mismo hablar de casos concretos de violaciones a los derechos humanos que hacerlo en términos abstractos. ${ }^{55}$ En los informes del primer periodo, los hechos violatorios a los derechos humanos señalados en las recomendaciones fueron la privación a la libertad personal (462 casos), maltrato, lesiones y golpes (187 casos), cobro indebido (117 casos), incumplimiento de un deber (114 casos), no acceso al servicio público (106 casos), afectación de un inmueble (87 casos), malos tratos (80 casos) y la negación al derecho de petición (60 casos). ${ }^{56}$ En cambio, los informes del

\footnotetext{
${ }^{54}$ Anónimo, entrevista con un funcionario de la Comisión de Derechos Humanos del Estado de Puebla, 11 de enero de 2017. Ejemplo de esto es la recomendación 19/97, que se refiere a la afectación a la construcción y propiedad del quejoso por parte del Ayuntamiento de Puebla, a raiz de la construcción del Circuito Interior. Tanto la ley que crea a la Comisión Estatal de Derechos Humanos de Puebla como el Reglamento, ambos reglamentos vigentes, no explicitan que las recomendaciones deberán emitirse por casos graves de violación a los derechos humanos, pero de manera implícita se da por entendido, ya que el artículo 97 de ley de la Comisión poblana sí dice que el instrumento de la conciliación será empleado cuando se trate de violaciones no graves a dichos derechos.

${ }^{55}$ Cfr. CDHEP, Informe anual de actividades 2012, Comisión de Derechos Humanos del Estado de Puebla, Puebla, 2013, pp. 40 y 44; Informe anual de actividades 2013..., pp. 48 y 67; Informe anual de actividades 2014..., pp. 44 y 72 ; Informe anual de actividades $2015 \ldots$.. pp. 52-53 y 79. El problema aqui es que el uso impreciso y ambiguo de los conceptos, lo que implica confusión para los lectores de los informes y para quienes revisan y sistematizan los datos. ${ }^{56}$ Cfr. CDHEP, Informe anual de actividades septiembre 2010-agosto 2011 y anexo septiembre-diciembre 2011, Co-
} 
segundo periodo evidencian que la vulneración a la seguridad jurídica fue la principal violación a los derechos humanos en las recomendaciones emitidas. En este mismo orden, le siguen la legalidad, la integridad y seguridad personal, la libertad, trato digno, la vida, la igualdad, la accesibilidad, la conservación del medio ambiente y no discriminación, el derecho de petición, la propiedad o posesión, el agua, la libertad de expresión, el trabajo y la protección de la salud. ${ }^{57}$ Además, en los informes 2012-2015 aparece un total de 525 casos de violaciones en las recomendaciones clasificadas por la Comisión como "otros hechos violatorios", ${ }^{5}$ lo que oculta la materia de las violaciones cometidas por las autoridades públicas y si éstas constituyen violaciones graves a los derechos humanos.

Por otro lado, en ningún informe del periodo 1993-2015 se presentan enlistadas en una gráfica las autoridades que fueron señaladas en las recomendaciones como las que más violaron los derechos humanos. Sin embargo, al revisarse los informes de actividades de la Comisión se encontró que las autoridades que presuntamente más violaron derechos humanos en las quejas fueron las policías municipales, la Policía Ministerial, el Ministerio Público, la Dirección General de los Centros de Rehabilitación Social y la Secretaría de Educación. ${ }^{59}$

\section{El cumplimiento de las Recomendaciones}

Se analizan a continuación dos recomendaciones (30/2009 y 15/2013) que tienen el estatus de cumplidas por las autoridades públicas municipales del estado de Puebla, ${ }^{60}$ las cuales se caracterizan por ser dos casos emblemáticos de violaciones graves a los derechos humanos. Al respecto, cabe decir

\footnotetext{
misión de Derechos Humanos del Estado de Puebla, Puebla, 2012, p. 141.

${ }^{57}$ Cfr. Informes anuales de actividades 2012, p. 44; 2013, p. 67; 2014, p. 72; 2015, p. 79. Una recomendación puede involucrar más de una violación a los derechos humanos.

${ }^{58}$ Cfr. CDHEP, Informe anual de actividades septiembre 2010-agosto 2011 y anexo septiembre-diciembre 2011, op. cit., p. 141.

${ }^{59}$ Cfr. CDHEP, Informe anual de actividades septiembre 2010-agosto 2011 y anexo septiembre-diciembre 2011, p. 140; Informe anual de actividades 2013, p. 138.

${ }^{60}$ En este trabajo sólo se tomó una muestra de dos recomendaciones sobre violaciones graves a los derechos humanos, a partir del hecho de que las recomendaciones emitidas por la Comisión poblana tienen la misma estructura y el mismo proceso de simulación en torno a la calificación de su cumplimiento. En realidad, las recomendaciones no restituyen los derechos vulnerados de las víctimas (véase el anexo en la sección $\mathrm{X}$ de este artículo), que es la finalidad principal de este instrumento de conclusión de quejas. Cfr. Lagunes López, Oscar Nicasio, op. cit., pp. 161162. En este mismo texto (/bid., pp. 163-167) el autor también analiza las recomendaciones (037/97 y 26/2008) emitidas por la Comisión de Derechos Humanos del Estado de Puebla obteniéndose los mismos resultados en relación con su cumplimiento.
} 
que la descripción del cumplimiento de las recomendaciones no se encuentra en ningún informe de actividades de la Comisión ni tampoco en su página electrónica, sino sólo el estatus entorno a su cumplimiento. Ello se debe, por un lado, a que el marco normativo del organismo no hace obligatoria la descripción del cumplimiento de las recomendaciones y, por el otro, al proceso de simulación política del cumplimiento de las recomendaciones. Lo anterior constituye una grave omisión, puesto que el cumplimiento real de las recomendaciones es el corazón y la razón de ser de este mecanismo de conclusión de quejas, el cual tiene por finalidad la restitución de los derechos vulnerados a las víctimas.

\subsection{Recomendación 30/2009}

Estatus actual: cumplida. Recomendación dirigida al presidente municipal de Acatlán de Osorio, Puebla. Derechos violados: abuso de autoridad, violación al principio de legalidad y seguridad jurídica y la vida. Fecha de emisión de la recomendación: 29 de mayo de 2009. Queja iniciada de oficio el 14 de octubre de 2008, por una nota informativa publicada en esta misma fecha en el periódico digital La Primera de Puebla, referente al asesinato de un joven de 14 años, de nombre Emmanuel Román Reyes, por policías de la región de Acatlán. De acuerdo con esta nota periodística, un grupo de jóvenes fue interceptado por elementos de la policía municipal de Acatlán de Osorio, la madruga del domingo después de salir de un baile público en el Rancho Sandía, ubicado en la población de Nuevos Horizontes, del municipio de Acatlán de Osorio. El agente Dimas Pérez Morales accionó accidentalmente su escopeta de cargo hiriendo por la espalda a Emmanuel, por lo que procedieron a trasladarlo al hospital general de aquel municipio, donde perdió la vida el día martes. Entre los agentes también se encontraban Alejandro Avilés Martínez, Víctor Manuel Moran Guzmán y el comandante Armando de Silvio Serna Noriega, que fueron identificados por los agraviados. Después de hacerles una revisión de rutina, los policías ordenaron que se retiraran del lugar si es que no querían ser detenidos también. ${ }^{61}$

Como resultado de la averiguación previa por el delito cometido en contra del joven que perdió la vida, se inició procedimiento penal en contra del agente Dimas por probable homicidio calificado de quien en vida llevara el

${ }^{61}$ Cfr. cDHeP, XVI Informe Anual de Actividades, Comisión de Derechos Humanos del Estado de Puebla, Puebla, 2009, p. 134. 
nombre de Emmanuel Román Reyes. Al confirmarse el delito de homicidio calificado, se le decretó al agente el auto de formal prisión o preventiva el 18 de octubre de 2008. ${ }^{62}$ Por otro lado, la Comisión encontró que los policías, particularmente el agente Dimas, cometieron abuso de autoridad, violación del principio de legalidad y seguridad jurídica, toda vez que hicieron uso de la fuerza más allá de la legalidad, se detuvo a los agraviados sin una orden de detención, como lo señala la Constitución, y se vulneró "el bien jurídicamente tutelado y que en la especie es la vida". ${ }^{63}$

El policía inculpado adujo en su declaración ministerial que "para ser policía municipal no recibió curso de capacitación alguno". ${ }^{64}$ Esta afirmación, a criterio de la Comisión, pone en evidencia que algunos elementos policiacos no cuentan con la capacitación y la formación básica necesaria que requiere el cargo para velar por la seguridad pública y cumplir sus funciones en estricto apego a la legalidad, salvaguardando siempre los derechos humanos de los ciudadanos. El organismo realizó dos recomendaciones al edil de Acatlán de Osorio. La primera, que "emita una circular al Director de Seguridad Pública y Tránsito Municipal de Acatlán de Osorio Puebla, a efecto de que instruya a los servidores públicos a su cargo, para que sujeten su actuar a la Constitución Política de los Estados Unidos Mexicanos y a las leyes que de ella emanan”. La segunda, que se den cursos para capacitar a los elementos policiacos de su municipio, para que empleen de manera adecuada sus armas de cargo, "preserven la vida e integridad de las personas y les permitan el libre ejercicio de sus derechos". ${ }^{65}$ Descripción del cumplimiento:

1. La autoridad responsable emitió la circular número MAP.07-09 al director de Seguridad Pública y Tránsito Municipal de Acatlán de Osorio, Puebla, a efecto de que sujetara su actuar a los lineamientos establecidos en la Constitución Política de los Estados Unidos Mexicanos, respetando la misma y las leyes que de ella emanen. / 2. El director de Seguridad Pública y Tránsito Municipal de Acatlán de Osorio, Puebla, mediante escrito de fecha 13 de julio de 2009, solicitó al Instructor del Consejo de Seguridad Pública del Estado de Puebla, su apoyo para capacitar a los elementos de la policía a su cargo,

\footnotetext{
${ }^{62}$ Recomendación Número 30/2009, Expediente: 10243/2008-I, p. 23 [Consulta: 01/02/2017]. Disponible en: http:// www.cdhpuebla.org.mx/pdf/Rec/09/30-2009.pdf.

${ }^{63}$ Ibid., p. 28.

${ }^{64}$ Ibid., p. 29.

${ }^{65} \mathrm{Ibid}$., p. 30.
} 
capacitación que daría inicio en esa misma fecha, con una duración de cuatro semanas y una asistencia de 17 elementos de la Policía Municipal de Acatlán de Osorio, Puebla. ${ }^{66}$

En cuanto a la descripción del cumplimiento de las dos recomendaciones sugeridas por la Comisión, las autoridades responsables dan cuenta de que fueron acatadas. Sin embargo, dichas recomendaciones buscan la prevención futura de la violación cometida por los agentes policiacos, mas no la reparación de los derechos que fueron vulnerados. Esto se deduce del hecho de que el organismo no solicita proceso administrativo de los policías que detuvieron arbitrariamente a las víctimas, a pesar de haber probado que los agentes judiciales cometieron abuso de autoridad y violaron el principio de legalidad y seguridad jurídica; todas ellas, faltas sancionables de acuerdo con la normatividad establecida, que llevarían a la inhabilitación de sus cargos y la indemnización económica a los deudos del joven finado. Sólo se da cuenta del delito del agente Dimas por homicidio calificado y de la declaración de Auto de Formal Prisión o Preventiva, pero no se menciona si fue suspendido de sus funciones. Las dos recomendaciones se quedaron a nivel de realizar investigaciones para considerarse cumplidas, pero no toman en cuenta los resultados positivos como parte fundamental para la reparación efectiva los derechos vulnerados.

\subsection{Recomendación 15/2013}

Estatus actual: cumplida. Enviada al presidente municipal de Tehuitzingo, Puebla, el 30 de junio de 2013. "Derechos Humanos vulnerados: Seguridad Jurídica, Legalidad, Igualdad, Integridad y Seguridad Personal y Trato Digno". ${ }^{67}$ Queja presentada ante la Comisión el 23 de marzo de 2012 por V1 a favor de V2 en contra de los elementos de la policía municipal, juez calificador, secretario general, regidor de Gobernación y coordinadora del Sistema para el Desarrollo Integral de la Familia; todas, autoridades de dicho municipio. En relación con los hechos que son motivo de la queja, se desprende que el día 3 de marzo de 2012 seis elementos de la policía municipal de dicha localidad detuvieron a V1, el cual fue sometido con diversos golpes en distin-

\footnotetext{
${ }^{66}$ Ibidem.

${ }^{67}$ CDHEP, Informe anual de actividades 2013, Comisión de Derechos Humanos del Estado de Puebla, Puebla, 2014, p. 140.
} 
tas partes del cuerpo y esposado mientras se encontraba fuera de su domicilio, ubicado en D1. Al llegar V2, pareja del agraviado, preguntó a los policías por qué lo trataban de esa manera, por lo que de inmediato fue arrestada por los agentes a base de jalones, retorciéndole el brazo y lanzándola a la batea de la unidad oficial de la policía municipal (ambos fueron detenidos por presentar intoxicación etílica y por hacer escándalo en la vía pública). V1 les informó a los oficiales que la trataran con cuidado porque estaba embarazada, pero ellos se rieron aduciendo que las machorras no se embarazan. V1 y V2 fueron subidos a la patrulla y trasladados a la comandancia municipal de Tehuitzingo; posteriormente, fueron ingresados a la cárcel a empujones.

Más tarde, la señora V2 comenzó a sentir molestias al grado de presentar sangrado vaginal y dolor en caderas y vientre, suceso que hicieron del conocimiento de los elementos policiacos que se encontraban en la comandancia, pero ignoraron la llamada de auxilio. ${ }^{68}$ Transcurridas algunas horas, un policía municipal entró a la celda de V2 para insultarla y propinarle varias patadas en su vientre, a partir de este momento la hemorragia no se pudo detener y se produjo el aborto. V1 le comentó al juez calificador del suceso, quien le dijo que el asunto lo tratarían después. Pasadas dos horas, entró el comandante de la Policía Municipal a la celda donde se encontraba la mujer V2, para trasladarla a la clínica de los Servicios de Salud Pública, donde le señalaron que necesitaría un ultrasonido y un legrado. Más tarde, la trasladaron al Hospital General de Acatlán pero no la hospitalizaron en ese momento, porque su esposo (V1) se encontraba en la comandancia. El juez calificador dejó en libertad a VI, para que pudiera acompañar a su esposa y le prestaran los servicios médicos correspondientes. ${ }^{69}$

La Comisión emitió dicha recomendación porque las autoridades señaladas en la queja, "elementos de la Policía Municipal y juez Calificador de Tehuitzingo", cometieron violaciones graves a los derechos humanos de las víctimas: "seguridad jurídica, legalidad, igualdad, integridad y seguridad personal y al trato digno". ${ }^{70}$ Sin embargo, esta institución no pudo comprobar que el aborto fue ocasionado por el maltrato que recibió la mujer al ser detenida:

\footnotetext{
${ }^{68}$ Cfr. CDHEP, Recomendación Número: 15/2013. Expediente: 2727/2012-C, pp. 2-3 [Consulta: 05/04/2017]. Disponible en http://www.cdhpuebla.org.mx/pdf/Rec/13/15-2013.pdf.

${ }^{69}$ Cfr. Ibid., p. 3

70 lbid., p. 12. Véase también p. 33.
} 
Por cuanto hace a las manifestaciones de queja por parte de los agraviados en el sentido de que el aborto que presentó V2, fue originado por los diversos maltratamientos y golpes inferidos por los elementos de la Policía Municipal de Tehuitzingo, Puebla, durante su detención y estancia en la primera sección de la Comandancia de dicha localidad, con lo que se podría haber vulnerado el derecho humano a la vida del producto de su embarazo; sin embargo, este organismo constitucionalmente autónomo, no contó con evidencia suficiente que así lo acreditara; por lo que no se hace pronunciamiento respecto de ese derecho humano, habida cuenta que los agraviados denunciaron ese hecho dentro de la averiguación previa AP1, misma que continua siendo integrada hasta la fecha de emisión de esta Recomendación; en consecuencia será el agente del Ministerio Público Investigador respectivo quien determinará sobre esa situación como delito, en términos de los artículos 15, 16 y 19, de la Ley Orgánica de la Procuraduría General de Justicia del Estado de Puebla. ${ }^{71}$

Las acciones recomendatorias que el organismo defensor dirigió al presidente de Tehuitzingo, Puebla, fueron cinco. La primera, "instruir a quien corresponda, a fin de que se tomen las medidas necesarias para reparar el daño ocasionado a los señores V1 y V2, respecto al pago de los gastos generados y que se generen por la atención médica y psicológica, que se haya requerido o requiera, derivada de las afectaciones a la integridad de su salud que se le ocasionaron [...] y remita a este organismo las pruebas de su cumplimiento". ${ }^{22}$ La segunda, "dar vista al contralor" para que "determine iniciar el procedimiento administrativo de investigación en contra de los elementos de la Policía Municipal [...] el juez Calificador [...] y en su oportunidad determine lo que en derecho proceda”, lo cual deberá hacer del conocimiento de este organismo. La tercera recomendación, que se capacite a los elementos policiacos de Tehuitzingo, Puebla, y al juez calificador municipal en relación con el "respeto y protección a los derechos humanos" consagrados en la legislación internacional, nacional y local, con la finalidad de evitar la repetición de dichos actos. Lo anterior deberá comunicarse a esta Comisión. La cuarta sugerencia, "emita una circular" con el objetivo de instruir a los elementos policiacos de Tehuitzingo y juez calificador, para que "sujeten su actuar al Orden Jurídico Mexicano, a los Tratados Internacionales” de los que México

\footnotetext{
${ }^{71}$ Ibid., pp. 27-28.

${ }^{72}$ CDHEP, Informe anual de actividades 2013, pp. 141-142.
} 
forme parte "y se abstengan de realizar actos que atenten contra la seguridad jurídica y legalidad de las personas; debiendo remitir las evidencias que demuestren su cumplimiento a este organismo". ${ }^{73}$ Por último, la quinta recomendación, que se proporcione a la Procuraduría General de Justicia del Estado la información que tenga a disposición, para que ésta "integre la averiguación previa” en contra de autoridades anteriormente señaladas como responsables de violar los derechos humanos de las víctimas". ${ }^{74}$

Descripción del cumplimiento:

1. Mediante oficio MTP/SG/0146/2013, de fecha 23 de agosto de 2013, suscrito por la autoridad responsable, dirigido a la presidenta del Sistema DIF Municipal de Tehuitzingo, Puebla; se advierte que se solicitó girara instrucciones para proporcionar atención médica y psicológica a los peticionarios, esta a su vez solicitó colaboración a la presidenta del Sistema DIF Municipal de Acatlán de Osorio, Puebla, a efectos de que la atención médica y psicológica les fuera proporcionada en la unidad básica de rehabilitación a su cargo, en virtud de lo anterior se señalaron diversas fechas para que los quejosos recibieran dicha atención.

2. Con oficio MTP/0125/2013, de fecha 31 de julio de 2013, suscrito por la autoridad responsable y dirigido al Contralor de ese Municipio, le instruyó para que en el ámbito de su competencia iniciara procedimiento administrativo de responsabilidades a los funcionarios involucrados, y con fecha 7 de agosto de 2013, el contralor municipal determinó iniciar dicho procedimiento.

3. Por cuanto hace a la capacitación de los elementos de la Policía Municipal y juez calificador de ese municipio, esta se llevó a cabo en el mes de septiembre de 2013, con una duración de 4 horas, bajo el tema Jornadas de actualización en Derechos Humanos, en colaboración con la Secretaría de Seguridad Pública del Estado de Puebla. La autoridad anexó copias de los reconocimientos expedidos a los asistentes.

4. Emitió las circulares números MTP/0136/2013, MTP/0137/2013 y MTP/0134/2013, de fecha 14 de agosto de 2013, mediante la cual instruyó al juez Calificador, al director de Seguridad Pública de Tehuitzingo, Puebla y a elementos de la Policía Municipal de Tehuitzingo, 
Puebla, a efecto de procurar respeto a la dignidad humana y a garantizar los derechos fundamentales de las personas.

5. Con el oficio MTP/0142/2013, de fecha 21 de agosto de 2013, suscrito por la autoridad responsable dirigido al agente del Ministerio Público investigador de Tehuitzingo, aportó pruebas dentro de la averiguación previa que se inició con los hechos que motivaron la presente recomendación. ${ }^{75}$

A partir de los datos anteriormente expuestos, se infiere que la queja tardó año y tres meses para ser concluida por emisión de una recomendación, y un año dos meses para ser cumplida por la autoridad a la que fue emitida. Sin embargo, al igual que en la recomendación anteriormente analizada, dicho cumplimiento no repara los derechos humanos vulnerados de las víctimas. En el detalle del cumplimiento de la primera acción, se observa que no se aporta información respecto a la indemnización de V1 y V2, a consecuencia de los gastos derivados de la atención médica recibida una vez puestos en libertad. En la descripción del cumplimiento de la segunda acción, se dice que fue comunicado a la Comisión que la Contraloría Municipal, que se inició procedimiento administrativo contra los responsables de violar los derechos humanos de las víctimas anteriormente señaladas. No obstante, no se proporcionan los resultados de dicho procedimiento, es decir, si fueron sancionados los responsables y qué tipo de sanción se les aplicó. Estas primeras dos acciones y la quinta son las que podrían haber permitido presionar a las autoridades para reparar el daño, pues son correctivas, pero la Comisión las ha calificado como cumplidas aunque no se mencionen los resultados y si estos repararon los derechos humanos vulnerados.

En cambio, las siguientes tres acciones son de carácter preventivo. Los cursos de capacitación en derechos humanos y la emisión de circulares a las autoridades señaladas como responsables de violar derechos humanos en la presente recomendación, para que respecten la dignidad humana y garanticen sus derechos fundamentales, son insuficientes y no logran prevenir la repetición futura de los actos violatorias que dieron lugar a la presente recomendación (acciones 3 y 4), puesto que la función preventiva de la Comisión se centra en casos particulares, a pesar de ser sistemático el origen de la vulneración de los derechos humanos. En cumplimiento de la quinta

${ }^{75}$ Solicitud de información pública, Infomex, folio 00093817, Respuesta de la CDHEP con Oficio CDH/DPIT/048/2017, del 7 de marzo de 2017. Clasificación Archivistica: Expediente 48/2017, Sección 12C, Serie 6. 
acción, tampoco logra reparar los derechos vulnerados. La redacción de la recomendación es estratégica, puesto que hace posible el cumplimiento de la recomendación desde la emisión de oficios por parte de la autoridad a quien fue dirigida la recomendación, pues tales acciones se cumplen desde el momento en que las autoridades refieren mediante oficios haberlas iniciado. La Comisión no toma en cuenta los resultados de dichas acciones sugeridas o recomendaciones para calificar cumplida una recomendación.

\section{Conclusión}

El desempeño de la Comisión poblana ha sido deficiente, puesto que los indicadores no muestran con objetividad si la conclusión de una queja, por cualesquiera de los instrumentos de conclusión, implica la restitución de los derechos vulnerados de las víctimas. ${ }^{76}$ Lo anterior, a pesar de que los datos obtenidos muestran un alto nivel de conclusión de quejas y un alto porcentaje de recomendaciones cumplidas; los números pueden manipularse por la institución, por esa razón el análisis de las dos recomendaciones mostró que su cumplimiento no es sinónimo de reparación de los derechos humanos de los afectados. ${ }^{77}$ La institución defensora local se encuentra sometida a un fuerte control político y financiero, lo cual merma sustantivamente su desempeño e impide que realice un trabajo serio en la defensa de los derechos humanos de las víctimas. ${ }^{78}$

\footnotetext{
${ }^{76}$ En un artículo especializado, Rubén A. Curiel hace referencia al deficiente desempeño de la Comisión de Puebla en los siguientes términos: "... nos encontramos a una Comisión estatal de Derechos Humanos debilitada y sometida, sin que haya podido tener nada más que una gestión gris y opaca frente a la cantidad tan grande de afrentas a los Derechos Fundamentales". Curiel Tejeda, Rubén Alberto, "Análisis de las violaciones cometidas a Derechos Humanos durante el sexenio de Rafael Moreno-Valle (2011-2017) en Puebla", en Hernández Avendaño, Juan Luis (coord.), Rafael Moreno-Valle Rosas (2011-2017). La persistencia del autoritarismo subnacional, Universidad Iberoamericana Puebla, Puebla, 2017, p. 108.

${ }^{77}$ Aplica para el caso poblano la conclusión que Alfredo Zavaleta extrae de su análisis sobre la gestión de la Comisión de Derechos Humanos del Estado de Veracruz, al afirmar que la lógica institucional de estos organismos es la siguiente: "... si se recomienda no se acepta; si se acepta no se cumple, y si se cumple no se hace daño. La condena moral de los responsables de violaciones que pertenecen a estas instituciones no pasa en la mayoría de los casos de simples recomendaciones sin efectos jurisdiccionales". Zavaleta Betancourt, Alfredo, "Los derechos humanos en Veracruz (1991-2006)", en Olvera, Alberto J. (coord.), La democratización frustrada. Limitaciones institucionales y colonización de la política de las instituciones garantes de derechos y de participación ciudadana en México, CIESAS/UV, México, 2010, p. 421.

${ }^{78}$ Ramírez, Gloria (coord.), Ombudsman y sociedad civil: retos y propuestas, Academia Mexicana de Derechos Humanos, México, 2007, p. 73. Este texto refiere que la posición de la Comisión poblana fue de franca alienación con el gobernador del estado en tres casos representativos de violaciones graves a los derechos humanos durante el 2005: las detenciones arbitrarias de la periodista Lydia Cacho y del defensor laboral Martín Barrios y la ingobernabilidad en el municipio de Ajalpan, puesto que "nunca representó un contrapeso para el mismo ni fue una mirada crítica ante los hechos".
} 
El control político y económico impide que la Comisión de Derechos Humanos de Puebla sea realmente autónoma. Éste es un factor crucial que explica la baja eficiencia del organismo. El control político se da mediante la intervención del Ejecutivo en el proceso de elección del Ombudsman, pues esta designación no se hace de manera democrática. No está ciudadanizada. En cambio, el control financiero se da a través de la reducción anual del presupuesto de la Comisión, puesto que el Congreso local ha recortado anualmente el porcentaje del presupuesto de egresos del gobierno del estado destinado a la Comisión. Tal es así que la institución defensora poblana es la que ha recibido el menor porcentaje del presupuesto (0.03\%) del Gobierno estatal, si se le compara con el de los 31 organismos públicos de derechos humanos $(O P D H)$ del país. Este dato también revela que para el Gobierno poblano cada vez es menos importante la defensa de los derechos humanos dentro del territorio estatal.

Para evitar el control financiero, debería establecerse en el artículo 15, fracción $\mathrm{X}$, de la ley de la Comisión poblana que su presupuesto no podrá ser menor al del año inmediato anterior; asimismo, que se le incremente el porcentaje del presupuesto de egresos que recibe del Gobierno estatal, por lo menos al porcentaje promedio anual $(0.11 \%)$ que ha recibido durante el periodo estudiado (1993-2015). En cuanto al proceso de elección del Ombudsman, debería ciudadanizarse y democratizarse. Es decir, los Ombudsman locales habrán de provenir de oNG defensoras de los derechos humanos de reconocido prestigio y no haber desempeñado cargos en el Poder Judicial.

Por otro lado, es contradictorio que en el periodo estudiado la tendencia en el tiempo muestre un incremento en el número de quejas recibidas, a la vez que un descenso en la emisión de recomendaciones, pues ello implica que la Comisión detecta cada vez más casos de presuntas violaciones a los derechos humanos, pero pocos casos de violaciones graves a los mismos. Las víctimas son excluidas del proceso de conclusión de expedientes de quejas, particularmente del cumplimiento de las recomendaciones. La Comisión de Derechos Humanos del Estado de Puebla no toma en consideración indicadores cualitativos, tales como el grado de satisfacción de las víctimas, para concluir los expedientes de queja. La satisfacción de las víctimas ante la "reparación” del agravio por parte de las autoridades públicas debería ser el indicador central para que la Comisión califique con mayor objetividad el cumplimiento de las recomendaciones.

Actualmente, el cumplimiento de las recomendaciones no es sinónimo de reparación de los derechos humanos vulnerados a las víctimas. La Comisión 
poblana califica como cumplidas recomendaciones que no han sido realmente cumplidas, si se entiende por cumplimiento el restablecimiento de los derechos fundamentales de las víctimas. Esto es así porque las recomendaciones están diseñadas para ser cumplidas con envíos de oficios por parte de las autoridades responsables del cumplimiento, sin que necesariamente implique el acatamiento de las acciones sugeridas en los puntos recomendatorios. Lo anterior implica una violación adicional a los derechos humanos de los afectados: la negación del derecho de las víctimas a la efectiva reparación de sus derechos vulnerados y su acceso a la justicia. Por otra parte, la institución defensora no publica en sus informes anuales de actividades ni en su página electrónica la descripción del cumplimiento de las recomendaciones, sino sólo el estado en el que éstas se encuentran, por ejemplo, cumplida, no aceptada, parcialmente cumplida, etc., lo que constituye una grave omisión constitucional del principio de máxima publicidad y una violación al derecho a la información pública. La obligatoriedad de hacer pública dicha información habrá de ser incorporada en la ley de la Comisión poblana y en su reglamento interno.

10. Anexo: Cuadro de análisis de recomendaciones (037/1997, 26/2008, 30/2009 y 15/2013)

\begin{tabular}{|c|c|c|c|c|}
\hline Recomendación & 037/1997 & $26 / 2008$ & $30 / 2009$ & $15 / 2013$ \\
\hline $\begin{array}{l}\text { Autoridad recep- } \\
\text { tora }\end{array}$ & $\begin{array}{l}\text { Procurador General } \\
\text { de Justicia del } \\
\text { Estado }\end{array}$ & $\begin{array}{l}\text { Procurador General } \\
\text { de Justicia del } \\
\text { Estado }\end{array}$ & $\begin{array}{l}\text { Presidente muni- } \\
\text { cipal de Acatlán de } \\
\text { Osorio, Puebla }\end{array}$ & $\begin{array}{l}\text { Presidente munici- } \\
\text { pal de Tehuitzingo, } \\
\text { Puebla }\end{array}$ \\
\hline Derecho violentado & $\begin{array}{l}\text { Detención ilegal y } \\
\text { tortura de Carlos } \\
\text { y Jorge López } \\
\text { Figueroa }\end{array}$ & $\begin{array}{l}\text { Homicidio de un } \\
\text { civil por un policía } \\
\text { judicial }\end{array}$ & $\begin{array}{l}\text { Abuso de autoridad, } \\
\text { violación a princi- } \\
\text { pio de legalidad y } \\
\text { seguridad jurídica } \\
\text { y la vida }\end{array}$ & $\begin{array}{l}\text { Seguridad Jurídica, } \\
\text { Legalidad, Igual- } \\
\text { dad, Integridad y } \\
\text { Seguridad Personal } \\
\text { y Trato Digno }\end{array}$ \\
\hline $\begin{array}{l}\text { Lugar de los he- } \\
\text { chos }\end{array}$ & $\begin{array}{l}\text { Zona metropolitana } \\
\text { de Puebla }\end{array}$ & $\begin{array}{l}\text { Tecamachalco, } \\
\text { Puebla }\end{array}$ & $\begin{array}{l}\text { Rancho la Sandía, } \\
\text { Acatlá de Osorio }\end{array}$ & Tehuitzingo, Puebla \\
\hline $\begin{array}{l}\text { Autoridades seña- } \\
\text { ladas }\end{array}$ & $\begin{array}{l}\text { Policía Judicial del } \\
\text { Estado }\end{array}$ & $\begin{array}{l}\text { Policía Judicial del } \\
\text { Estado }\end{array}$ & $\begin{array}{l}\text { Policía municipal } \\
\text { de Acatlán }\end{array}$ & $\begin{array}{l}\text { Policía municipal, } \\
\text { juez calificador, } \\
\text { secretario gene- } \\
\text { ral, regidor de } \\
\text { Gobernación y } \\
\text { coordinadora del } \\
\text { Sistema para el } \\
\text { Desarrollo Integral } \\
\text { de la Familia }\end{array}$ \\
\hline
\end{tabular}




\begin{tabular}{|c|c|c|c|c|}
\hline $\begin{array}{l}\text { Acciones } \\
\text { sugeridas }\end{array}$ & $\begin{array}{l}\text { 1. Se inicie } \\
\text { averiguación } \\
\text { previa. 2. Se inicie } \\
\text { procedimiento } \\
\text { administrativo y, si } \\
\text { se determina algún } \\
\text { delito, proceda a } \\
\text { sancionar. 3. Gire la } \\
\text { orden para que se } \\
\text { inicie procedimien- } \\
\text { to administrativo y } \\
\text { averiguación previa } \\
\text { por posible delito } \\
\text { del médico legista }\end{array}$ & $\begin{array}{l}\text { 1. Instruya a los } \\
\text { mandos medios } \\
\text { para que ejerzan } \\
\text { mayor vigilancia } \\
\text { sobre sus subal- } \\
\text { ternos. } 2 \text {. Se inicie } \\
\text { proceso administra- } \\
\text { tivo. 3. Emita una } \\
\text { circular a la Policía } \\
\text { Judicial del Estado } \\
\text { para que cumpla } \\
\text { con su deber } 4 \text {. Se } \\
\text { inicie procedimien- } \\
\text { to administrativo. }\end{array}$ & $\begin{array}{l}\text { Abuso de autoridad, } \\
\text { violación a princi- } \\
\text { pio de legalidad y } \\
\text { seguridad jurídica } \\
\text { y la vida. }\end{array}$ & $\begin{array}{l}\text { 1. Se tomen las } \\
\text { medidas necesarias } \\
\text { para reparar el } \\
\text { daño. 2. Se inicie } \\
\text { procedimiento ad- } \\
\text { ministrativo. 3. Se } \\
\text { capacite a los ele- } \\
\text { mentos policiacos } \\
\text { y juez calificador. } 4 . \\
\text { Emitir una circular. } \\
\text { 5. Proporcione } \\
\text { información a la } \\
\text { Procuraduría para } \\
\text { que ésta integre la } \\
\text { averiguación previa }\end{array}$ \\
\hline $\begin{array}{l}\text { Descripción del } \\
\text { cumplimiento }\end{array}$ & $\begin{array}{l}\text { Recepción de ofi- } \\
\text { cios sin resultados. } \\
\text { No se describen los } \\
\text { resultados. }\end{array}$ & $\begin{array}{l}\text { Recepción de ofi- } \\
\text { cios sin resultados. } \\
\text { No se describen los } \\
\text { resultados. }\end{array}$ & $\begin{array}{l}\text { Recepción de ofi- } \\
\text { cios sin resultados. } \\
\text { No se describen los } \\
\text { resultados. }\end{array}$ & $\begin{array}{l}\text { Recepción de ofi- } \\
\text { cios sin resultados. } \\
\text { No se describen los } \\
\text { resultados. }\end{array}$ \\
\hline Sanciones & No & No & $\begin{array}{c}\text { Auto de formal } \\
\text { prisión }\end{array}$ & No \\
\hline $\begin{array}{l}\text { Restitución de } \\
\text { derechos humanos }\end{array}$ & No & No & No & No \\
\hline $\begin{array}{l}\text { Tiempo de } \\
\text { cumplimiento }\end{array}$ & eses & días & Mes y medio & 1 mes 23 días \\
\hline
\end{tabular}

Fuente: información con base en los informes anuales 1997, 2008, 2009 y 2013, y en las respuestas a solicitudes de información pública: solicitud de información pública, folio Infomex 00093817, Respuesta de la CDHEP con Oficio CDH/DPIT/048/2017, del 7 de marzo de 2017. Clasificación Archivistica: Expediente 48/2017, Sección 12C, Serie 6.

\section{ReFERENCIAS}

Álvarez Icaza Longoria, Emilio, "Situación de los Organismos Públicos de Derechos Humanos de las entidades federativas”, en Ibáñez Aguirre, José Antonio y Salcedo González, Sandra (coords.), Ombudsman: asignatura pendiente en México, Universidad Iberoamericana, México, 2013.

, Para entender los derechos humanos en México, Nostra, México, 2009.

Asamblea General de las Naciones Unidas, Principios de París o Principios Relativos al Estatuto y Funcionamiento de las Instituciones Nacionales de Protección y Promoción de los Derechos Humanos, ONU, París, 1991, Apartado B, núm. 2. Disponible en http://hrlibrary.umn.edu/instree/Sparisprinciples.pdf.

CNDH, Manual de Derechos Humanos: conceptos elementales y consejos prácticos, México, Comisión Nacional de los Derechos Humanos, Cadenas Huma- 
nas, 2003 [Consulta: 22/07/2017]. Disponible en http://www.cdhmorelos. org.mx/biblioteca/DH 4.pdf.

CDHEP, Informe anual de actividades 2015, Comisión de Derechos Humanos del Estado de Puebla, Puebla, 2016.

. Informe anual de actividades 2014, Comisión de Derechos Humanos del Estado de Puebla, Puebla, 2015.

. Informe anual de actividades 2013, Comisión de Derechos Humanos del Estado de Puebla, Puebla, 2014.

. Informe anual de actividades 2012, Puebla, Comisión de Derechos Humanos del Estado de Puebla, 2013.

. Informe anual de actividades septiembre 2010-agosto 2011 y anexo septiembre-diciembre 2011, Comisión de Derechos Humanos del Estado de Puebla, Puebla, 2012.

. XVI Informe Anual de Actividades, Puebla, Comisión de Derechos Humanos del Estado de Puebla, 2009.

- VII informe anual de actividades 1999-2000, Puebla, Comisión Estatal de Defensa de los Derechos Humanos, 2000.

- Recomendación Número 30/2009, Expediente: 10243/2008-I, p. 23 [Consulta: 01/02/2017]. Disponible en http://www.cdhpuebla.org.mx/pdf/ Rec/09/30-2009.pdf.

. Recomendación Número: 15/2013. Expediente: 2727/2012-C, pp. 2-3 [Consulta: 05/04/2017]. Disponible en http://www.cdhpuebla.org.mx/pdf/ Rec/13/15-2013.pdf.

CoIDH, Informe anual 2012, San José de Costa Rica, Corte Interamericana de Derechos humanos, 2012 [Consulta: 07/04/2017]. Disponible en http://www. corteidh.or.cr/docs/informes/spa_2012.pdf.

Curiel Tejeda, Rubén Alberto, “Análisis de lass violaciones cometidas a Derechos Humanos durante el sexenio de Rafael Moreno-Valle (2011-2017) en Puebla”, en Hernández Avendaño, Juan Luis (Coord.), Rafael Moreno-Valle Rosas (2011-2017). La persistencia del autoritarismo subnacional, Universidad Iberoamericana Puebla, Puebla, 2017, p. 108.

Faz Mora, Martín, Evaluación integral de la estructura y desempeño de la Comisión Estatal de Derechos Humanos (CEDH) de San Luis Potosí bajo parámetros internacionales, Tesis de Maestría en Derechos Humanos y Democracia, México, FLACSO-México, 2008.

Lachenal, Cécile y Pulido, Miguel, "Un grito en el desierto. Notas sobre el (mal) uso del lenguaje institucional de la $C N D H$, a la luz de algunas de sus recomendaciones”, en Ibáñez Gutiérrez, José Antonio y Salcedo González, Sandra (coords.), Ombudsman: asignatura pendiente en México, México, Universidad Iberoamericana, 2013, pp. 15-38.

Lachenal, Cécile, Martínez, Juan Carlos y Moguel, Miguel, Los Organismos Públicos de Derechos Humanos en México. Nuevas instituciones, viejas prácticas, Fundar, México, 2009. 
Lagunes López, Oscar Nicasio y Noriega Esparza, Guillermo, "Diagnóstico al desempeño de la Comisión Estatal de Derechos Humanos de Sonora, 19922012”, Revista Legislativa de Estudios Sociales y de Opinión Pública, vol. IX, núm. 17, enero-junio, 2016, pp. 71-100.

Lagunes López, Oscar Nicasio, "La simulación en el cumplimiento de las recomendaciones. El caso de la Comisión de Derechos Humanos del Estado de Puebla, México, 1993-2015”, Revista Latinoamericana de Derechos Humanos, vol. XXVIII, núm. 1, 2017, pp. 147-173.

Mayer-Serra, Carlos Elizondo y Magaloni Kerpel, Ana L., Nuestros caros defensores de los derechos humanos: el caso de la Comisión Nacional de Derechos humanos, CIDE, México, 2010.

Ramírez, Gloria (Coord.), Ombudsman y sociedad civil: retos y propuestas, Academia Mexicana de Derechos Humanos, México, 2007.

Shanik, David, “Jorge Ramón Díaz nuevo magistrado del TSJ Puebla”, Puebla Online, 15 de julio de 2011 [Consulta: 22/02/2017]. Disponible en http://www.pueblaonline.com.mx/index.php?option=com k2Ctview=itemctid=15194:jorge-ramón-d\%C3\%ADaz-nuevo-magistrado-del-tribunal-superior-de-justicia-de-puebla\&tItemid=127.

Venegas, Sonia, Origen y devenir del ombudsman. ¿Una institución encomiable?, Universidad Autónoma de México, México, 1988.

Yáñez Velasco, David, "El sistema ombudsman más caro del mundo... ¿y el más ineficiente?”, Espiral, Estudios sobre Estado y Sociedad, vol. XXII, núm. 63, mayo-agosto, 2015, pp. 185-220.

Zavaleta Betancourt, Alfredo, "Los derechos humanos en Veracruz (1991-2006)", en Olvera, Alberto J. (Coord.), La democratización frustrada. Limitaciones institucionales y colonización de la politica de las instituciones garantes de derechos y de participación ciudadana en México, México, CIESAS/ UV, 2010, pp. 407-446.

Solicitudes de Acceso a la Información Pública

Respuesta a solicitud de información pública por sistema Infomex puebla con número de folio 00701016, del 19 diciembre de 2017.

Respuesta de la CDHEP a solicitud de información pública con número de folio infomex 00700616, del 19 de diciembre de 2016.

Respuesta a solicitud de información pública Infomex folio núm. 00700816 del 19 de diciembre de 2016;

Respuesta a solicitud de información pública Infomex folio núm. 00700916 del 19 de diciembre de 2016.

Respuesta a solicitud de información pública Infomex folio núm. 00700016, del 19 de diciembre de 2016.

Solicitud de Información pública núm. de folio Infomex 00093517, respuesta de la CDHEP con Oficio No. CDH/DPIT/029/2017, del 7 de marzo de 2017. 
Solicitud de Información pública núm. de folio Infomex 00093617, respuesta de la CDHEP con Oficio No.: CDH/DPIT/035/2017, del 7 de marzo de 2017.

Solicitud de información pública, folio Infomex núm. 00093817, Respuesta de la $C D-$ HEP con Oficio CDH/DPIT/048/2017, del 7 de marzo de 2017. Clasificación Archivística: Expediente 48/2017, Sección 12C, Serie 6.

\section{Entrevistas}

Funcionario anónimo de la Comisión de Derechos Humanos del Estado de Puebla, 11 de enero de 2017.

Marcia Maritza Bullen Navarro, expresidenta de la Comisión de Derechos Humanos del Estado de Puebla, periodo 2008-2011, 8 de marzo de 2017.

Rubén Alberto Curiel Tejeda, coordinador de la Maestría en Derechos Humanos, Universidad Iberoamericana, Puebla, 22 de febrero de 2017.

\section{Legislación}

Congreso del Estado de Puebla, Reglamento Interno de la Comisión de Derechos Humanos del Estado de Puebla, Artículo 11. Periódico Oficial, Tomo CDLXVI, Número 11, Segunda Sección, "Cuatro Veces Heroica Puebla de Zaragoza”, viernes 28 de febrero de 2014 [Consulta: 23/03/2017]. Disponible en http://transparencia.cdhpuebla.org.mx/index.php/articulo-11/4-articulo-i.

, Ley de la Comisión de Derechos Humanos del Estado de Puebla. Reforma publicada en el Periódico Oficial, 19 de mayo de 2014 [Consulta: 23/03/2017]. Disponible en http://atlixco.gob.mx/atlixco/transparencia/2014/marconormativo/LeydelaComisióndeDerechosHumanosdelEstadodePuebla.pdf. , Constitución Política del Estado Libre y Soberano de Puebla, Artículo 142. Reforma publicada en el Periódico Oficial, Tomo CDXXXV, No. 11, Séptima Sección, del 25 de julio de 2011 [Consultado: 28/07/2017]. Disponible en http://www.cdhpuebla.org.mx/transparencia/images/fraccionI/Periodico_Oficial_Estado_AutonomiaCDHEP.pdf;

, Ley que crea la Comisión Estatal de Defensa de los Derechos Humanos. Publicada en el Periódico Oficial, Tomo CCXLVII, No. 49, Segunda Sección, del 18 de diciembre de 1992 [Consulta: 28/07/2017]. Disponible en http:// transparencia.cdhpuebla.org.mx/index.php/articulo-11/4-articulo-i. 